\title{
Numerical Simulation of Torsional Response Control of a Plan-Eccentric Mass Distribution Building by Using Magnetorheological Dampers
}

\author{
Manuel T. Braz-Cesar, Pedro L.P. Folhento, Rui C. Barros
}

\begin{abstract}
Wind and earthquake loads can cause coupled lateral-torsional deformations in building structures due to stiffness and/or mass eccentricities. Simple and regular structural configurations are usually recommended in designing seismic resistant systems to ensure optimal distribution of mass and stiffness in order to reduce torsional effects. However, these structures generally present irregular geometry due to other design requirements resulting in a complex three-dimensional dynamic behavior. In this regard, structural control has become a novel approach to reduce torsional seismic effects in asymmetric-plan building systems. Smart structures based on semi-active control systems are capable to improve significantly the seismic response of these structures with low power requirements, which represent a significant advantage over active systems. This paper presents a numerical simulation of a semi-active based control system using MagnetoRheological (MR) dampers to minimize the coupled lateral-torsional seismic response of a two-story framed building. A parametric study is carried out to evaluate the seismic behavior of the structure taking into account the effect of different mass eccentricities. The results show that it is possible to evaluate and validate the effectiveness of the semi-active control approach to reduce the structural seismic response for planeccentric or irregular mass distributions.
\end{abstract}

For the published version of record document, go to:

http://dx.doi.org/10.1109/CONTROLO.2018.8514552 
